\title{
Acute Esophageal Damage in Patients with Inoperable Non- small Cell Lung Cancer Treated with Concurrent and Sequential Chemoradiotherapy
}

\author{
Crvenkova Simonida*, M. Popova \\ University Clinic of Radiotherapy and Oncology, Faculty of Medicine, Ss Cyril and Methodius University of Skopje, Skopje, \\ Republic of Macedonia
}

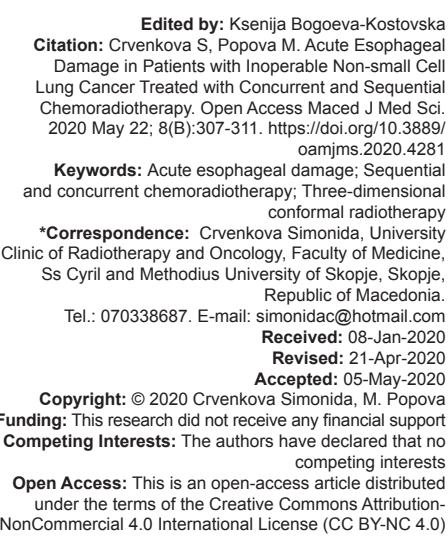

Abstract

BACKGROUND: Acute esophageal damage may be a dose-limited factor for application the full planning radiotherapy (RT) dose in patients with inoperable non-small cell lung cancer (NSCLC). A combination of chemotherapy and RT may increase esophageal toxicity, but three-dimensional (3D) conformal RT offers better sparing of the organs at risk.

AIM: The purpose of this study was to show the incidence and degree of acute esophageal damage in lung cancer patients treated with sequential and concurrent chemoradiotherapy.

MATERIALS AND METHODS: The total number was 73 patients, of whom 26 (34.7\%) had previously received sequential chemotherapy with a four-cycle followed by RT. In the second concurrent group, 47 (65.3\%) patients were received concomitant chemotherapy and $\mathrm{RT}$

RESULTS: Of the 73 patients included in the study, $43(57.3 \%)$ did not present any grade of esophagitis during the treatment. In the sequential group, $73.1 \%$ presented no esophagitis and in the concurrent group, $49 \%$, respectively. Although there were differences between the two groups, none were statistically significant.

CONCLUSIONS: The reason for the good tolerability of the combination of chemotherapy and RT for inoperable NSCLC patients was using 3D conformal RT. Further improvements may be obtained with more sophisticated RT or radioprotective drugs.

\section{Introduction}

Lung cancer remains a worldwide epidemic. Approximately 1.2 million people die from lung cancer each year. Non-small cell lung cancer (NSCLC) represents $>80 \%$ of all lung cancers. Of the patients with NSCLC, $60-70 \%$ present with Stage III or IV disease [1]. In the late 1980s, radiotherapy (RT) was the standard treatment for inoperable lung cancer patients. Randomized trials and a 1995 overview subsequently showed that combination chemoradiotherapy was superior to RT alone. Many chemotherapeutic agents active in NSCLC possess radiosensitizing properties, thereby improving the probability of local control. In addition, chemotherapy administered concurrent with thoracic radiation may act systemically and potentially eradicate distant micrometastases. Several studies showed the feasibility of the cisplatin-etoposide combination plus RT for patients with Stage III disease [2], [3]. Acute esophagitis occurring $\leq 90$ days after treatment is a common side effect of patients undergoing RT for thoracic tumors. Concurrent chemoradiotherapy results in a $15-25 \%$ rate of severe (RT oncology group RTOG) Grade 3 or greater acute esophagitis [4] that can require hospitalization, invasive diagnostic tests (endoscopy) surgical intervention (percutaneous endoscopic gastrostomy tube) or RT breaks that could lower local tumor control [5], [6], [7], [8], [9]. Acute esophagitis occurs during RT and often persists for several weeks after RT. The symptoms of severe esophagitis (Grade 3 or greater) typically peak 4-8 weeks from the beginning of RT. Late esophageal damage, typically stricture and associated dysphagia, develops 3-8 months after RT [10]. Abnormal esophageal motility can be noted within 3-4 weeks from RT alone and as early as 1 week after starting concurrent chemoradiotherapy [11]. The adult esophagus length is approximately $25 \mathrm{~cm}$ and is defined by its external contour on axial computed tomography (CT) images. It is recommended that the entire length of the esophagus, from the cricoid cartilage to the gastroesophageal junction, be identified, requiring that portion of the neck and upper abdomen be included in the planning CT scan. In some of the studies [10], [11], the cervical esophagus was not included, casing the absolute esophageal volume to be $20 \%$ smaller than if its entirety had been 
contoured. The degree of damage of the esophagus is proportional with the volume involved in the radiation fields and with daily radiation dose and total radiation dose. In the literature, there are small numbers of the studies analyzed esophageal damage in patients with inoperable NSCLC treated with concurrent and sequential chemoradiotherapy. The purpose of this study is to show the incidence and degree of acute esophageal damage in lung cancer patients treated with sequential and concurrent chemoradiotherapy.

\section{Materials and Methods}

This study was started at the Clinic of RT and Oncology in Skopje, March 2010. To evaluate the treatment results, a study of 73 patients was randomly assigned to one of the two treatment arms. In the sequential arm, 26 (34.7\%) patients had previously received sequential chemotherapy with four cycles of carboplatin and etoposide followed by conformal RT. In the second concurrent arm, 49 (65.3\%) patients received concurrent chemotherapy of cisplatin and etoposide and conformal RT. Eligible 73 patients were aged between 18 and 70 years, had an Eastern Cooperative Oncology Group Score $\leq 1$, and had $\leq 10 \%$ weight loss in the period of 3 months before inclusion. They have previously untreated histological or cytological proven NSCLC, unrespectable Stage IIIA-N2 disease, or Stage IIIB disease without pleural effusion. Stage IIIB disease was assigned either by N3 (contralateral mediastinal or supraclavicular nodes) or by $\mathrm{T} 4$ from invasion of mediastinal structures. The following laboratory values were required: Leukocytes $\geq 1.5 \times 10^{3} / \mathrm{l}$, platelets $\geq 100 \times$ 10/l, and AST and ALT $\leq 2 \times$ the upper limit of the referent rang. Ineligibility criteria were as follows: Uncontrolled infection, or fever over $38^{\circ} \mathrm{C}$, unstable cardiovascular disease, and previous malignancy.

Patients were randomly assigned to receive sequential or concurrent therapy. In the sequential arm, 26 patients received four cycles of chemotherapy. They were administered first, consisting of carboplatin (AUC $\times 6$ ) on day 1 and etoposide on days 1-3, repeated every 3 weeks. The RT began 4 weeks after the fourth cycle of chemotherapy administration. Chemotherapy and RT began simultaneously in concurrent arm consisted of 47 patients. The RT schedule was identical to that in the sequential arm. The first cycle with cisplatin $30 \mathrm{mg} / \mathrm{m}^{2}$ and etoposide $100 \mathrm{mg} / \mathrm{m}^{2}$ was administered on days 1-3 and the second 3-days cycle was administered the last 3 days of RT. After 4 weeks of concurrent chemoradiotherapy schedule, two cycles of consolidation chemotherapy began, consisting of carboplatin $(A \cup C \times 6)$ and etoposide $100 \mathrm{mg} / \mathrm{m}^{2}$ on day $1-3$.

Conformal RT at both arms consisted of $60 \mathrm{~Gy}$ in 30 fractions of 2 Gy per fraction, for 5 days a week given over a period of 6 weeks. A treatment planning CT was required to define the gross tumor volume (GTV). Each patient was positioned in an immobilization device-wing board in the treatment position on a flat table. CT slices with $5 \mathrm{~mm}$ thickness were obtained starting from cricoid cartilage and extending inferiorly to the level of the L1 vertebral body. The GTV, clinical target volume (CTV), planning target volume (PTV), and normal organs were outlined on all CT slices. The normal tissues contoured included lungs (as the total lung volume), heart, spinal cord, and esophagus. The CTV included the entire GTV plus $0.5 \mathrm{~cm}$ and the PTV included CTV plus another $0.5 \mathrm{~cm}$ adding margin. PTV44 was treated with parallel-opposed anterior-posterior fields and PTV60 was treated with any combination of fields depends of spinal cord constrain. Contouring of target volumes and normal organs esophagus, spinal cord, heart, and lung was performed on each slide. The external surface of the esophagus was delineated on each axial plane of the planning CT scan from the level of the lower end of the cricoid cartilage to the gastroesophageal junction. Patients had their entire esophagus, including esophageal internal lumen contoured. Maximum acceptable doses for dose-limiting organs were lung V20 $<37 \%$, and esophageal maximum dose V45 of $<40 \%$, V55 of $<28 \%$. Dose distribution and dosevolume histograms for the esophagus were calculated according to the Varian system.

During the course of RT, patients were observed at least weekly and more often if the need for clinical evaluation and treatment of complaints. Acute esophageal toxicity was determined during the weekly visit and at clinical follow-ups after 1 month and 2 months, respectively. Acute esophageal toxicity $<3$ months was graded by the RTOG criteria. These criteria are grading acute esophageal damage as Grade 1 due to mild dysphagia or odynophagia, requiring topical anesthetic, non-narcotic agents, or soft diet, Grade 2 moderate dysphagia or odynophagia requiring narcotic agents or liquid diet, Grade 3 severe dysphagia or odynophagia with deshydratation or weight loss $>15 \%$ of pre-treatment baseline requiring nasogastric feeding, and Grade 4 complete obstruction, ulceration, perforation, or fistula. If RT had to be delayed for more than 7 days, the patient was withdrawn from the study. Patients with evidence of progression at any time were removed from the study but continued to be evaluated for survival and toxicity. Survival and the interval to recurrence or progression were measured from the date of the first treatment session.

\section{Results}

From 2010 to 2013, at the University Clinic of RT and Oncology in Skopje, 73 patients were enrolled. 
The median OS was 13 months for the patients in the sequential arm and 19 months for those in the concurrent treatment arm $(p=0.0039)$ Figure 1 .

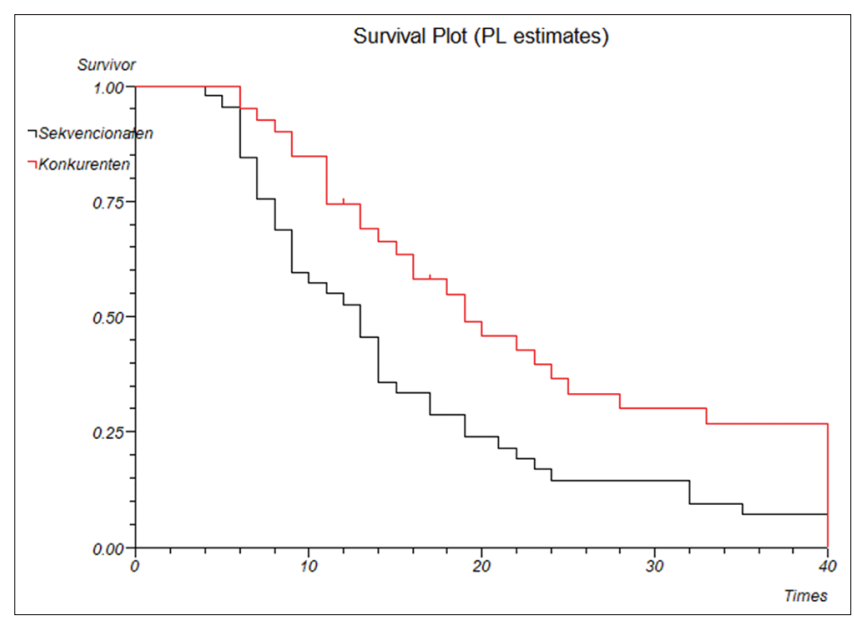

Figure 1: Overall survival according to treatment, concurrent versus sequential chemoradiotherapy

For 73 patients included in the study, 43 (57.3\%) did not present any grade of esophagitis during the treatment. In the sequential group, $73.1 \%$ presented no esophagitis and in the concurrent group, $49 \%$, respectively. Although there were differences between the two groups, it was not statistically significant. There was not any Grade 4 esophageal damage in both groups. Tables 1 and 2 summarize the esophageal damage in both treatment groups according to radiation doses. The risk of esophagitis was $22 \%$, in patients whose esophageal volume (V50) received $<30 \%$ of prescribed dose in comparison, the risk of esophagitis was $71 \%$, in patients whose V 50 received dose higher than $30 \%(p=0.0009)$.

\section{Discussion}

This study was a prospective report of treatmentrelated acute toxicities of the esophagus in a patient with lung cancer that was administered concurrent and sequential RT and chemotherapy. Several studies have shown that, compared to RT alone, the addition of concurrent or sequential chemoradiotherapy to radiation appears to lower esophageal tolerance [12]. A meta-analysis of 19 randomized trials of a radical cathode-ray tube (CRT) versus RT alone, including concurrent and sequential systemic therapy, reported that the addition of chemotherapy increases acute esophagitis by approximately 5 times [13]. In a study by Byhardit et al., in patients with locally advanced NSCLC, the incidence of severe acute esophagitis with standard RT alone $60-69$ Gy/30 was $1.3 \%$; concurrent chemotherapy increased this to $14-49 \% 24-5$. Radical RT alone results in significantly lower rates of Grade 3 or higher esophagitis (1-2\%) [14].

Older techniques using two-dimensional (2D) planning are more likely to cause side effects than modern technologies [15]. In comparison with the 2D RT, three-dimensional (3D) conformal RT results in Grade 2 esophagitis in 32\%, Grade 3 in $10-17 \%$, and Grade 4 in $0.9 \%$ [16], [17]. The incidence of severe acute esophagitis in our study was lower than for other studies of patients with lung cancer treated with 3D-CRT [18], [19]. It is well known that acute esophagitis affects the quality of the life of lung cancer patients, and may precipitate a break in radiation treatment. In this study, RT treatment interruptions due to severe esophagitis were not observed. The median dose administered in our study was 60 Gy which was slightly lower the prescribed dose of $66 \mathrm{~Gy}$ in other conformal RT. Acute radiation injuries usually occur in the $3^{\text {rd }}-4^{\text {th }}$ week of RT and tend to increase severity toward the end of treatment [20]. These findings also showed that the appearance of Grade 3 or higher acute esophagitis was similar to other published studies [21]. None of patient experienced Grade 4 esophagitis. Although dose-volume parameters are commonly used to analyze the risk of acute esophagitis, there is a significant degree of dissimilarity among the other published studies regarding which dose-volume parameters have the most dominant effect on the risk of acute esophagitis [22]. Some reports show esophageal volume $40 \mathrm{~Gy}$ associated with acute esophagitis [18], others mentioned no association between the risk of acute esophagitis and volumes of the esophagus [8]. At present, it is not possible to identify a single best threshold parameters associate significantly with mild

Table 1: Grade of esophagitis according to RT doses

\begin{tabular}{|c|c|c|c|c|c|c|c|c|}
\hline \multirow[t]{2}{*}{ Radiation dose } & \multicolumn{4}{|c|}{ Sequential arm (\%) } & \multicolumn{4}{|c|}{ Concurrent arm (\%) } \\
\hline & 0 & 1 & 2 & 3 & 0 & 1 & 2 & 3 \\
\hline $40 \mathrm{~Gy}$ & $22(84.6)$ & $1(3.8)$ & $3(11.5)$ & 0 & $30(61.2)$ & $8(16.3)$ & 9 (18.4) & $2(4.1)$ \\
\hline $60 \mathrm{~Gy}$ & $20(76.9)$ & 0 & $6(23.1)$ & 0 & $25(51.0)$ & $7(14.3)$ & $15(30.6)$ & $3(6.1)$ \\
\hline End of RT & 19 (73.1) & $1(3.8)$ & $6(23.1)$ & 0 & $28(84.6)$ & $4(8.2)$ & $14(28.6)$ & $3(6.1)$ \\
\hline
\end{tabular}

Table 2: Irradiation doses and analgesia

\begin{tabular}{|c|c|c|c|c|c|c|c|c|}
\hline \multirow[t]{2}{*}{ Radiation dose } & \multicolumn{4}{|c|}{ Sequential arm (\%) } & \multicolumn{4}{|c|}{ Concurrent arm (\%) } \\
\hline & 0 & 1 & 2 & 3 & 0 & 1 & 2 & 3 \\
\hline $40 \mathrm{~Gy}$ & $22(84.6)$ & $1(3.8)$ & 0 & $3(11.5)$ & $30(61.2)$ & $11(22.4)$ & $4(8.2)$ & $4(8.2)$ \\
\hline 60 Gy & $21(80.8)$ & $1(3.8)$ & $1(3.8)$ & $3(11.5)$ & $25(51.0)$ & $12(24.4)$ & $4(8.2)$ & $8(16.3)$ \\
\hline End of RT & $20(76.9)$ & $1(3.8)$ & $2(7.7)$ & $3(11.5)$ & 31 (63.3) & $7(14.3)$ & $2(4.1)$ & $9(18.4)$ \\
\hline
\end{tabular}


to severe acute esophagitis. Exempting the entire esophageal length/volume from the high-dose radiation region is extremely difficult. Decreasing the radiation dose delivered to a part of the esophageal margin might be feasible with better RT techniques, in particular, the studies we analyzed illustrate a clear trend demonstrating that volumes receiving $>40-50$ Gy correlated significantly with acute esophagitis [22]. A study by Gomez et al. [23] showed that patients with NSCLC treated with intensity-modulated RT (IMRT) have the highest rate of Grade 3 acute esophagitis when compared with 3DCRT and RT. The authors speculate that this could be due to the "lower-dose bath" received by the esophagus with IMRT, whereas 3DCRT and RT allow complete or partial sparing of the esophagus. The Belderbos et al. study [18] finds that when accepting a $30 \%$ risk of developing esophagitis grade $\geq 2$, a maximum volume of $50 \%$ of the esophagus can be irradiated to $35 \%$ Gy. This dose/ volume recommendation for the esophagus is also given by QUANTEC [24]. Our results indicated that in the treatment of lung cancer patients, highly conformal $\mathrm{RT}$ reduces the risk of esophagitis to a minor problem. For better esophageal spearing and providing a better quality of life for our lung cancer patients in the future, we planning to use 18-fluoro-deoxy-glucose positron emission tomography CT scan in the RT treatment planning process.

\section{Conclusions}

The reason for the good tolerability of the combination of chemotherapy and RT for inoperable NSCLC patients in our study was using 3D conformal RT. Further improvements may be obtained with more sophisticated RT and treatment planning or further research in radioprotective agents.

\section{References}

1. World Health Organization Statistics. Available from: http://www. who.int/mediacentre/factsheets/fs297/en. [Last accessed on 2017 Dec 21].

2. Le Chevalier T, Arriagada R, Quoix E, Ruffie P, Martin M, Tarayre $\mathrm{M}$, et al. Radiotherapy alone versus combined chemotherapy and radiotherapy in nonresectable NSCLC: First analysis of a randomized trial in 353 patients. J Natl Cancer Inst. 1991;83(6):417-23. https://doi.org/10.1093/jnci/83.6.417 PMid: 1847977

3. Curran WJ Jr, Paulus R, Langer CJ, Komaki R, Lee JS, Hauser S, Movsas B, Wasserman T, et al. Phase III comparison of seguential vs. Concurrent chmoradiation for patients with unresected stage III NSCLC: Initial report of RTOG 9410. Proc ASCO. 2000;19:484a. https://doi.org/10.1016/

\section{s0169-5002(00)80304-9}

4. Cox JD, Stetz J, Pajak TF. Toxicity criteria of the radiation therapy oncology group (RTOG) and the European organization for research and treatment of cancer (EORTC). Int J Radiat Oncol Biol Phys. 1995;31(5):1341-6.

PMid:7713792

5. Furuse K, Fukuaka M, Kawahara M, Nishikawa H, Takada $Y$, Kudoh S, et al. Phase III study of concurrent versus sequential thoracic radiotherapy in combination with mitomycin, vindesine and cisplatin in unresectable stage III non-small-cell lung cancer. J Clin Oncol. 1999;17(9):2692-9. https://doi.org/10.1200/ jco.1999.17.9.2692

PMid: 10561343

6. Timmerman R, McGarry R, Yiannoutsos C, Papiez L, Tudor K, DeLuca J, et al. Excessive toxicity when treating central tumors in phase II study of stereotactic body radiation therapy for medically inoperable early stage lung cancers. J Clin Oncol. 2006;24(30):4833-9. https://doi.org/10.1200/jco.2006.07.5937 PMid:17050868

7. Choi GB, Shin JH, Song HY, Lee YS, Cho YK, Bae Jl, et al Fluoroscopically guided balloon dilation for patients with esophageal stricture after radiation treatment. J Vasc Interv Radiol. 2005;16(12):1705-10. https://doi.org/10.1097/01. rvi.0000179813.93992.9e

PMid:16371539

8. Singh AK, Lockett MA, Bradley JD. Predictors of radiationinduced esophageal toxicity in patients with NSCLC treated with three-dimensional conformal radiotherapy. Int $\mathrm{J}$ Radiat Oncol Biol Phys. 2003;55(2):337-41. https://doi.org/10.1016/ s0360-3016(02)03937-8

PMid: 12527046

9. Qiao WB, Zhao YH, Zhao YB, Wang RZ. Clinical and dosimetric factors of radiation induced esophageal injury: Radiation induced esophageal toxicity. World J Gastroenterol. 2005;11(11):2626-9. https://doi.org/10.3748/wjg.v11.i17.2626 PMid:15849822

10. Ahn SJ, Kahn D, Zhou S, Yu X, Hollis D, Shafman TD, et al. Dosimetric and clinical predictors for radiation induced esophageal injury. Int J Radiat Oncol Biol Phys. 2005;61(2):335-47.

PMid:15667951

11. Chapet O, Kong FM, Lee JS, Hayman JA, Haken RK. Normal tissue complication probability modeling for acute esophagitis inpatients treated with conformal radiation therapy for NSCLC. Radiother Oncol. 2005;77(2):176-81. https://doi.org/10.1016/j. radonc.2005.10.001 PMid: 16256230

12. Bradley J, Deasy JO, Benzen S, El-Naqa I. Dosimetric correlates for acute esophagitis in patients treated with radiotherapy for lung carcinoma. Int J Radiat Oncol Biol Phys. 2004;58(4):1106-13. PMid: 15001251

13. O'Rourke N, Roque IF, Bernado NF, Macbeth F. Concurrent chemoradiotherapy in non-small cell lung cancer. Cochrane Database Syst Rev. 2010;6;CD002140.

PMid:20556756

14. Byhardit RW, Scott C, Sause WT, Emami B, Komaki R, Fisher B, et al. Response, toxicity, failure patterns and survival in five radiation therapy oncology group (RTOG) trials of sequential and/or concurrent chemothterapy and radiotherapy for locally advanced non-small-cell carcinoma of the lung. Int $\mathrm{J}$ Radiat Oncol Biol Phys. 1998;42(3):469-78. https://doi.org/10.1016/ s0360-3016(98)00251-x PMid:9806503

15. Fairchild A. Side effects of palliative radiation therapy. In: Lutz S, Chow E, Hoskin P, editors. Radiation Oncology in Palliative 
Cancer Care. West Sussex, UK: Wiley-Blackwell; 2013. p. 43-60. https://doi.org/10.1002/9781118607152.ch5

16. Palma DA, Senan S, Oberije C, Belderbos J, de Dios NR, Bradley JD, et al. Predicting esophagitis after chemotadiation therapy for NSCLC: An individual patient data meta-analysis. Int J Radiat Oncol Biol Phys. 2013;87(4):690-6.

PMid:24035329

17. Bradley JD, Paulus R, Komaki R, Masters G, BlumenscheinG, Schild $\mathrm{S}$, et al. Standard-dose versus high-dose conformal radiotherapy with concurrent and consolidation carboplatin plus paclitaxel with or without cetuximab for patients with stage IIIA or IIIB non-small-cell lung cancer (RTOG 0617): A randomised, twoby-two factorial phase 3 study. Lancet Oncol. 2015;16(2):18799. https://doi.org/10.1016/s1470-2045(14)71207-0 PMid:25601342

18. Belderbos J, Heemsbergen $W$, Hoogeman $M$, Pengel $K$, Rossi M, Lebesque $\mathrm{J}$, et al. Acute esophageal toxicity in NSCLC patients after high dose conformal radiotherapy. Radiother Oncol. 2005;75(2):157-64. https://doi.org/10.1016/j. radonc.2005.03.021

PMid: 15890421

19. Liao ZX, Komaki RR, Thames HD Jr., Liu HH, Tucker SL, Mohan R, et al. Influence of technologic advances on outcomes in patients with unresectable, locally advanced NSCLC receiving concomitant chemoradiotherapy. Int J Radiati Oncol Biol Phys. 2010;76(3):775-81. https://doi.org/10.1016/j.jijrobp.2009.02.0 PMid: 19515503

20. Wei X, Liu HH, Tucker S, Liao Z, Hu C, Mohan R, et al. Risk factors for acute esophagitis in NSCLC patients treated with concurrent chemotherapy and three-dimensional conformal radiotherapy. Int J Radiat Oncol Biol Phys. 2006;66(1):100-7. https://doi.org/10.1016/j.ijrobp.2006.04.022

PMid: 16839700

21. Wemer-Wask M, Scott C, Paulus R, Curran WJ Jr, Byhardt R. Correlation between acute esophagitis and late pneumonitis in patients with locally advanced NSCLC receiving concurrent thoracic radiotherapy; a multivariate analysis of Radiation Therapy Oncology Group database. ASCO Annu Meet. 2002;21:1192-299.

22. Takeda K, Nemoto K, Satio H, Ogawa Y, Takai Y, Yamada S. Dosimetric correlations of acute esophagitis in lung cancer patients treated with radiotherapy. Int J Radiat Oncol Biol Phys. 2005;62(3):626-9.

PMid:15936536

23. Gomez DR, Tucker SL, Martel MK, Mohan R, Balter PA, Guerra JL, et al. Predictors of high-grade esophagitis after definitive three-dimensional conformal therapy, intensitymodulated radiation therapy, or proton beam therapy for NSCLC. Int J Radiat Oncol Biol Phys. 2012;84(4):1010-6. https://doi.org/10.1016/j.jrobp.2012.01.071

PMid:22920974

24. Marks LB, Yorke ED, Jackson A, Haken RK, Constine LS Eisbruch $A$, et al. Use of normal tissue complication probability models in the clinic. Int J Radiat Oncol Biol Phys. 2010;76 Suppl 3:S10-9.

PMid:20171502 